\title{
ESTUDO COMPARATIVO DE FASES DE APÔIO SEMELHANTES, NOS DIVERSOS ANDAMENTOS DO CAVALO
}

\section{Armando Chieffi}

Assistente

(27 figuras)

\section{INTRODUÇÃO}

No decorrer do estudo que fizemos sôbre os andamentos, e durante as nossas observações, por ocasião do ensino prático, na Cadeira de Zootecnia Especial e Exterior dos Animais Domésticos da Faculdade de Medicina Veterinária de São Paulo, verificamos a presença de bases de sustentação semelhantes nas diferentes modalidades de andar do cavalo, bases essas que, pela simples notação, seriam incapazes de levar o estudioso à dedução dessa ou daquela modalidade de andamento.

Com efeito, quer no trote, quer no galope, quer no passo e ainda na marcha pròpriamente dita e na marcha trotada, há fases de apôio bipedais diagonais. E assim, no estudo dos demais tipos de locomoção, notaremos a presença de apoios monopedais (anteriores e posteriores) ; bipedais (diagonais e laterais) ; tripedais (anteriores e posteriores) e quadrupedais, além de fases de suspensão.

Procurando diferenciar as fases de apôio semelhantes, determinando a modalidade a que pertencem, - o que seria impossível, como dissemos, pelo simples exame das notações, que revelam as bases de sustentação, mas não dão idéia da disposição tomada pelos membros, única que permite a diferenciação —, propuzemo-nos recorrer à cinematografia, para fazer um estudo comparativo daquelas fases de apôio semelhantes, nos diferentes andamentos.

Para isso, interpretamos as películas de propriedade do Departamento de Zootecnia Especial, da Faculdade de Medicina Veterinária, que focalizam animais em andamento, em câmara lenta.

Conseguimos, assim, estudar as diversas fases, obtendo as silhuetas que ilustram êste trabalho, cópia fiel do filme, atravéz de decalque do mesmo.

Sòmente em alguns casos, tais como no trote de corrida e na andadura de corrida, andamentos cujos filmes não possuíamos, recorremos às fotografias de tratados. 
Visando facilitar o estudo comparativo, baseamo-nos sôbre o número de membros em apôio, e após indicar os andamentos que possuem as mesmas fases de sustentação, anterior ou posterior, revelando o modo de seu aparecimento, não entrando na descrição dos andamentos em particular, que consideramos matéria conhecida, discutimos 'o assunto, tendo em vista os desenhos esquemáticos.

Este estudo demonstrará a posição real que os membros tomam nas diversas fase do andamento, podendo servir de orientação na arte de reproduzir as imagens, visto como não são raros os exemplos de pintura que idealizam posições em apôio ou em suspensão, que não existem na locomoção do cavalo.

Não serắo abordadas, com detalhes, as angulações dos membros, visto como essa parte diz respeito a outro trabalho em preparo.

\section{APARECIMENTO DE FASES DE APÔIO SEMELHANTES, NOS DIVERSOS ANDAMENTOS}

APÔIO MONOPEDAL: - Na andadura, no trote, no galope, na marcha pròpriamente dita e na marcha trotada, encontra-se, normalmente, ou em alguns casos, o apôio monopedal, momento em que o pêso do corpo do animal é sustentado sôbre um único membro, anterior ou posterior.

No caso da andadura, já nos referimos em trabalho apresentado $\left({ }^{*}\right)$ não ter sido possível encontrar a notação típica, apontada pelos tratados, em que os apoios dos bípedes laterais seguiriam sem interrupção, de modo que, ao se elevar um bípede, cairia o outro, e as bases seriam sempre em bípedes laterais.

As nossas observações nos levaram à conclusão da existência de modalidades de andadura, uma das quais, em tudo semelhante à marcha pròpriamente dita, revelou a presença de apôio monopedal, sempre posterior, esquerdo e direito. A sua presença se dá após o apôio diagonal e antes da fase de sustentação lateral, que é longa.

Outros Autores, como SмIтH, falam da existência de apoios monopedais na andadura, anterior e posterior, intercalados entre apoios diagonais breves, o que não foi possível verificar nos casos por nós examinados.

No trote normal não há bases monopedais e estas só aparecem em algumas variedades do andamento, em que desaparece a associação dos bípedes diagonais. Assim, no trote de corrida, pelo apôio anteci-

(*) Contribuição para o estudo da localização do Centro de Gravidade no corpo dos animais domésticos e dos fatôres que produzem seu deslocamento temporário ou permanente - Deslocamento do Centro de Gravidade nas Atitudes, nos Movimentos sobre o Lugar, nos andamentos e nos saltos do cavalo. - A. Chieffi e L. Homem de Melo. - Rev. Fac. Med. Vet. (Vol. 1 - Fasc. 2 - Set. 1939). 
pado dos membros anteriores, após cada período de suspensão, aparece um apôio monopedal anterior (esquerdo ou direito) (fig. 5), e depois da fase de sustentação diagonal, ainda pela elevação antecipada do membro anterior, destaca-se um apôio monopedal posterior (esquerdo ou direito) (fig. 2).

No galope normal, dois apoios monopedais aparecem no decurso de um passo completo: um posterior, imediatamente após o período de suspensão (fig. 3) e outro anterior, do membro oposto em diagonal ao que iniciou o passo, em seguida ao apôio tripedal e ocasionado pela elevação, ao mesmo tempo, dos bípedes diagonais, associados no galope normal (fig. 6).

Quando a velocidade do andamento aumenta, há dissociação do apôio associado em diagonal e antecipação da quéda dos posteriores, de modo a fazer desaparecer o apôio tripedal, normalmente presente, e determinar novas fases de apoios monopedais, que se seguem intercaladas por bases bipedais. Em um galope de corrida, à direita, por exemplo, todos os membros, em determinada ocasião, têm que sustentar o pêso do corpo, e a seqüência das fases de apôio monopedais é a seguinte: - monopedal posterior esquerdo (fig. 2-b), monopedal posterior direito (fig. 4), monopedal anterior esquerdo (fig. 7) e monopedal anterior direito.

Na marcha, quer no tipo que classificamos como marcha pròpriamente dita, quer na trotada, houve casos de apoios monopedais $\left(^{*}\right)$, sempre posteriores (esquerdos e direitos), aparecendo após as fases bipedais diagonais, pela mais rápida elevação dos membros anteriores (Fig. 1).

A presença dessa base de apôio monopedal, contudo, não foi por nós verificada em tôdas as 24 notações examinadas e, pelo quadro jà referido em trabalho que apresentamos, que poderá ser consultado, fez seu aparecimento em 18 casos.

APôIo BIPEDAL: - Em todos os andamentos, quer na andadura quer no trote, no galope, no passo e na marcha, há fases de apôio bípedais, que podem ser laterais e diagonais.

$\mathrm{Na}$ andadura típica, a única base que deveria existir seria a bipedal lateral. Nas modalidades por nós examinadas, embora havendo sempre franca predominância dessa base de sustentação (fig. 8), elas eram acompanhadas por outros apoios de curta duração.

No trote normal, é a base de apôio bipedal diagonal a única existente (fig. 11).

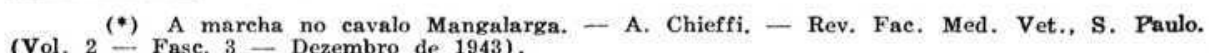


No galope normal e de corrida há bases diagonais, que são intercaladas entre apôios tripedais, no caso do andamento normal (fig. 12-a); e entre os apôios monopedais (fig. 12-b), em se tratando do galope de corrida, onde, como frizamos, as únicas sustentações são a monopedal e bipedal.

No passo há bases de apôio laterais e diagonais, ambas após as fases tripedais (fig. 9 e 13).

$\mathrm{Na}$ marcha, os apoios bipedais são laterais e diagonais, às vezes com predominância dos primeiros sôbre os segundos, outras vezes dêstes sôbre aquêles, havendo casos de completo desaparecimento dos laterais (marcha trotada bem acentuada) (fig. $10 \mathrm{e} \mathrm{14).}$

Normalmente, as bases laterais seguem as monopedais e antecedem as tripedais, enquanto que as diagonais se situam após a tripedal.

APÔIO TRIPEDAL: - Em variedades de andadura, no galope normal, no passo e na marcha, existem apoios tripedais.

$\mathrm{Na}$ andadura, êles se colocam entre os apôios bipedais, podendo aparecer após os laterais (tripedal anterior - fig. 17) os após os diagonais (tripedal posterior - fig. 21).

No galope normal, o apôio tripedal segue o monopedal que inicia o passo após o período de suspensão, pela quéda do bipede diagonal associado, constituindo um apôio tripedal anterior (fig. 18), como faz também seu aparecimento, em seguida à fase de apôio bipedal diagonal -, pela queda do membro anterior que posteriormente dará nome ao galope, formando agora uma base de apôio tripedal posterior (fig. 22). Esta fase tripedal desaparece no galope de corrida e tôdas as vezes que houver dissociação dos membros diagonais, associados no galope normal.

No passo há sempre fases tripedais, ora anteriores (fig. 19), ora posteriores (fig. 23), intercaladas com as bipedais diagonais e laterais.

Na marcha pròpriamente dita e na marcha trotada, regra geral, para os casos examinados, houve apôio tripedal, sempre anterior (fig. 20 ), que segue as bases bipedais laterais (20 vezes nas 24 notações estudadas em câmara lenta) ou diagonais (4 vezes).

APÔIO QUADRUPEDAL: - Só foi verificado em uma modalidade de trote: o trote marchado (fig. 24).

PERÍDO DE SUSPENSÃo: - Normalmente, quer no trote, quer no galope, há um momento em que o animal se encontra em completa suspensão, sem membro algum em contato com o solo. E' esta a razão pela qual êsses andamentos são denominados saltados (fig. 25 e 26). 
Na andadura há uma variedade, a andadura de corrida ("pacing" ou "raking), em que se intercala um período de suspensão entre os apoios laterais (fig. 27).

\section{INTERPRETAÇÃO DAS FIGURAS ESQUEMÁTICAS \\ APOIOS MONOPEDAIS \\ 1. $\left.{ }^{\circ}\right)$ - Posteriores}

a) Apôio monopedal posterior, na marcha (fig. 1)

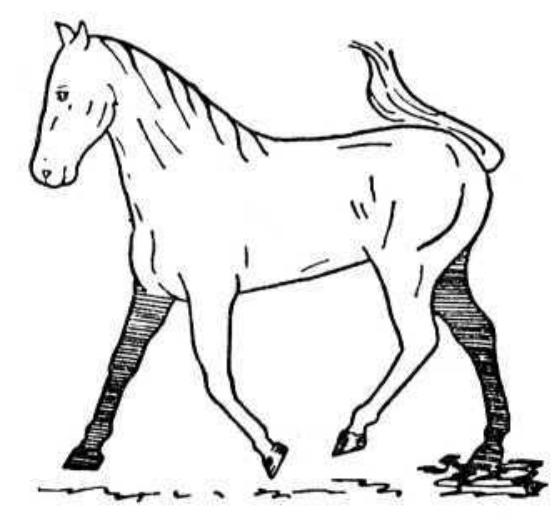

Fig. 1

O membro posterior em apôio, no caso direito, distendido para trás, apresenta sua máxima abertura no ângulo do jarrete. $O$ anterior do mesmo lado, distendido para frente, prepara-se para entrar em apôio e fomar a base lateral, neste andamento. $\mathrm{O}$ outro bípede lateral, no caso o esquerdo, em suspensão, se acha flexionado, convergindo em sua extremidade.

De um modo geral, podemos admitir que a disposição dos membros em suspensão e mesmo a orientação dos raios ósseos do membro em apôio, com excessão, lògicamente, da parte terminal dêsse membro, lembra o período de suspensão do trote normal, antes da queda do diagonal.

b) Apôio monopedal posterior, no trote de corrida (fig. 2)

Essa fase de apôio, muito breve, mostra o membro posterior em sustentação em máxima distensão, enquanto o anterior em diagonal vai iniciar sua flexão no joelho. O bípede diagonal em suspensão achase bem flexionado, principalmente o membro anterior, que é levado bem para $o$ alto. 
c) Apôio monopedal posterior, no galope (fig. 3)

O membro em apôio segue, mais ou menos, orientação vertical e o que se encontra em suspensão avança sob o corpo, indo se colocar tanto mais para frente, quanto mais rápido fôr o andamento.

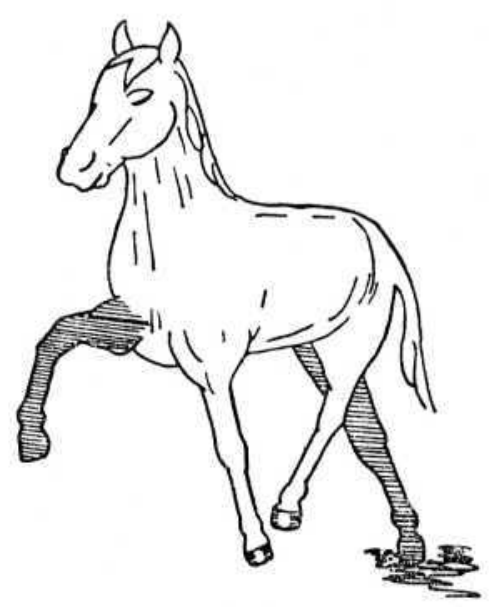

Fig. 2

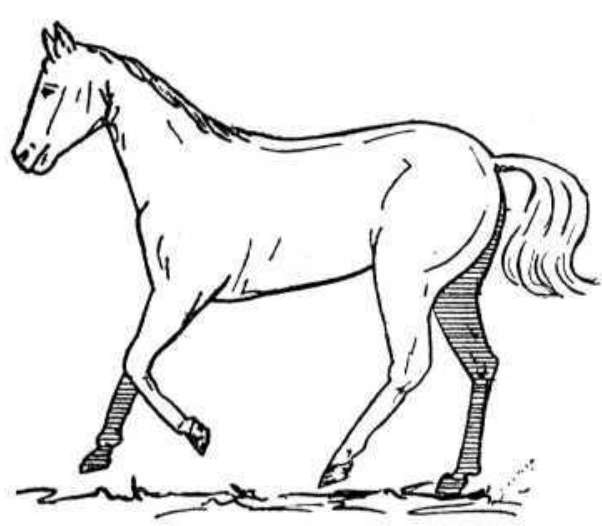

(a)

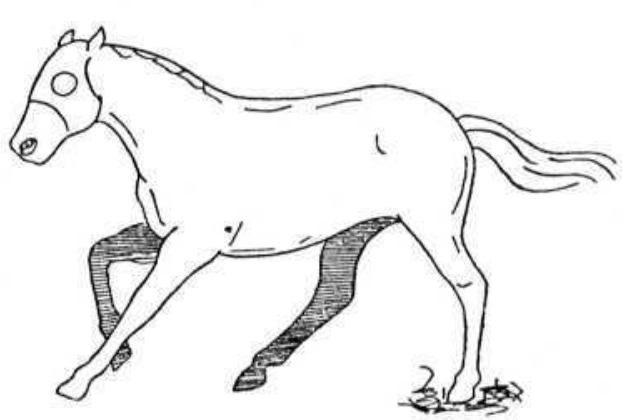

(b)

Fig. 3

Os anteriores, ambos em suspensão, um se acha muito pouco flexionado (o do mesmo lado do membro posterior em apôio), enquanto o outro apresenta flexão acentuada no joelho.

O fechamento dos ângulos umero-radio-cubital e carpo metacarpianos se acentua, a medida que aumenta a velocidade do galope, chegando ao seu máximo no galope de corrida, (fig. $3 \mathrm{~b}$ ). 
d) Apôio monopedal posterior, no galope de corrida (fig. 4)

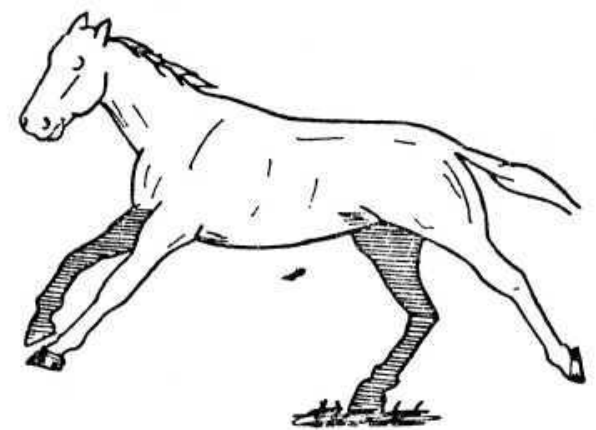

Fig. 4

Vimos, ao descrever o mecanismo de aparecimento dos apoios monopedais posteriores no galope de corrida, que um dêles aparece em consequência da dissociação do bípede diagonal, associado no galope normal.

O membro posterior que avança sob o corpo durante o apoio do membro pélvico que iniciou o passo, e que foi referido na descrição da fig. 3, entra em fase de sustentação, permanecendo no solo - no galope de corrida - mesmo depois que seu congênere se eleva. E' o que se verifica na Fig. 4, onde vemos que o membro posterior em suspensão se acha distendido para trás.

Dos anteriores, um se acha distendido (o oposto em diagonal ao posterior em apôio) e o outro flexionado, ambos para frente das linhas de aprumo.

$\left.2 .^{\circ}\right)$ - Anteriores

e) Apôio monopedal anterior, no trote de corrida (fig. 5)

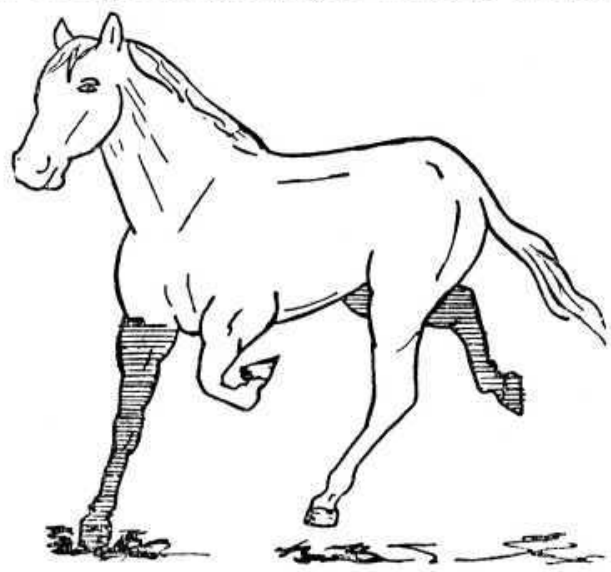

Fig. 5 
O membro anterior que se apoia, nessa fase do "flying trot", bem distendido, contrasta com o outro anterior, intensamente flexionado, a ponto do talão por vezes, chegar a ferir o codilho (daí a proteção dessa região com almofadas).

Os membros posteriores, ambos em suspensão, se orientam mais ou menos como no período de suspensão do trote normal, apenas mais afastados entre sí, devido à maior flexão daquele que se orienta para trás da linha de aprumo posterior.

f) Apôio monopedal anterior, no galope (fig. 6)

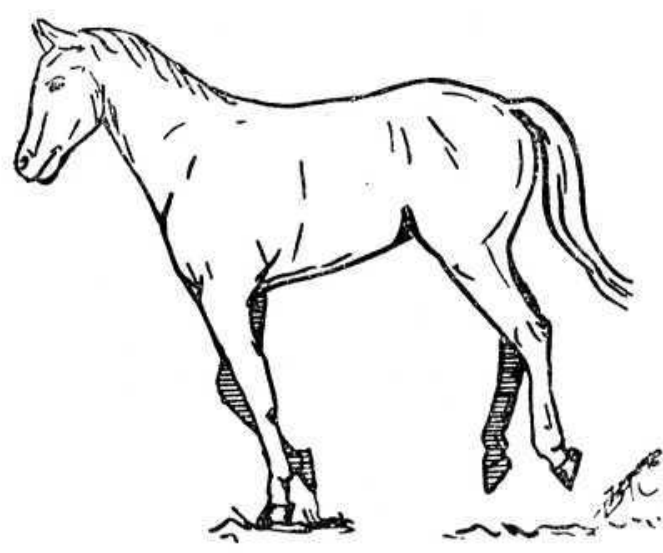

(a)

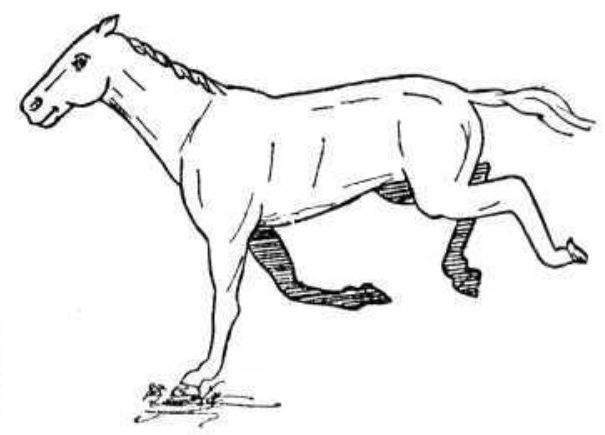

(b)

Fig. 6

O membro em apôio, no fim da fase de sustentação do galope normal orienta-se para trás da linha de aprumo, dando aspecto debruçado ao animal. O anterior em suspensão acha-se também deslocado para trás, flexionado no joelho.

Os posteriores, ambos lançados para trás, se flexionam visivelmente no jarrete, e o fechamento da articulação talo-crural se acentua no galope de corrida, quando os membros posteriores têm sua flexão maior (fig. 6b). Na silhueta representada na fig. $6 \mathrm{~b}$, iniciava-se 0 apôio monopedal anterior e a orientação dêsse membro é oblíqua para frente, tornando-se, na evolução do andamento, vertical e inclinada para trás, levando o corpo em seu deslocamento para frente. 
g) Apôio monopedal anterior, no galope de corrida (fig. 7)

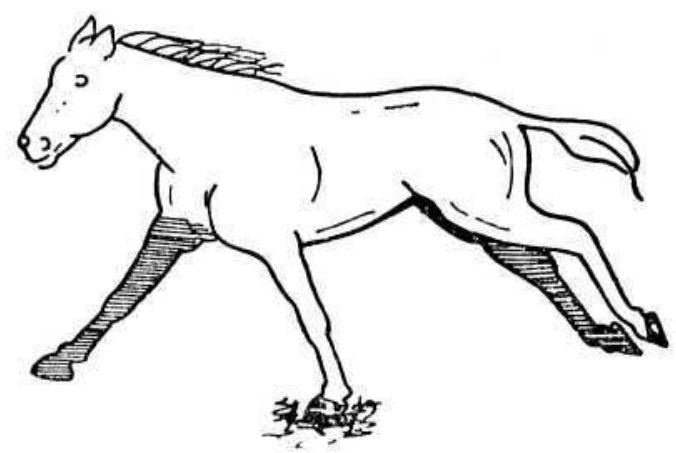

Fig. 7

$\mathrm{O}$ anterior em apôio se acha sob o corpo. Todos os membros em suspensão se encontram completamente distendidos; o anterior para frente, os posteriores para trás das linhas de aprumo.

A disposição dos membros em suspensão, nas fases de apôio monopedais posterior e anterior dos andamentos examinados, e a própria orientação dos membros pélvico e torácico, em alguns casos, é suficiente para diferenciar os tipos de locomoção, não dando margens a possíveis confusões.

$\left.1 .^{\circ}\right)$ - Laterais

\section{APOIOS BIPEDAIS}

a) Apôio bipedal lateral, na andadura (fig. 8)

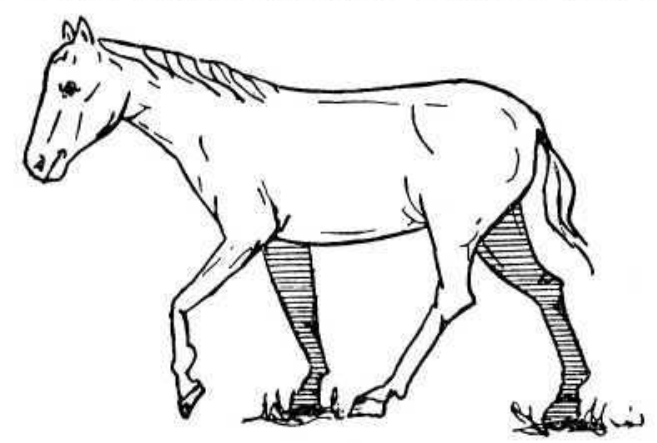

Fig. 8

$\mathrm{Na}$ andadura, os membros laterais tendem a se manter em orientação paralela, sempre oblìuamente.

E' o que acontece tanto com o bípede lateral que entra em apôio, como com o que permanece em suspensão, que se deslocam, mais ou menos, sincrônicamente. 
0 desenho da fig. 8 representa a andadura de um potro filmado no último período de apôio do bípede lateral direito, quando os membros esquerdos, em suspensão, se localizam adiante dos que se encontram em apôio.

Compreende-se, assim, inversamente, que o início de um apôio lateral se caracteriza pelos membros distendidos, ficando o bípede em suspensão, sempre, localizado posteriormente.

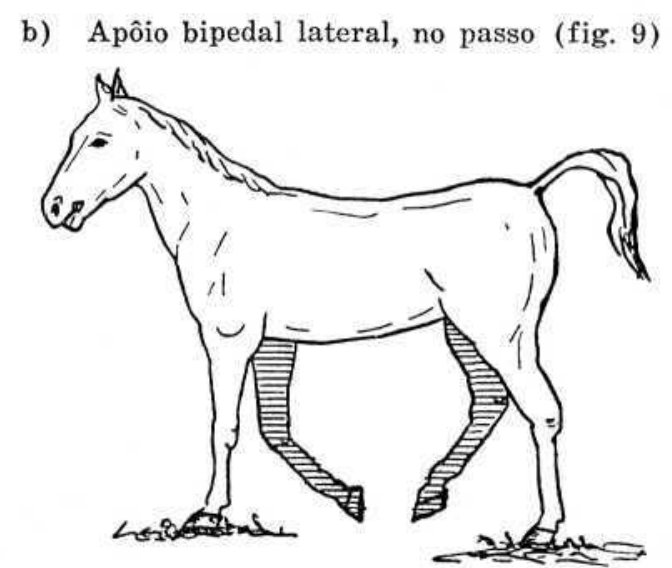

Fig. 9

No passo, os membros laterais em apôio se conservam mais ou menos verticais e paralelos, enquanto o bípede em suspensão converge. Isto significa que sempre será notado, nessa fase de apôio do passo, dois membros laterais em suspensão que se aproximam pelas suas extremidades, localizadas dentro do bípede em apôio.

c) Apôio bipedal lateral, na marcha (fig. 10)

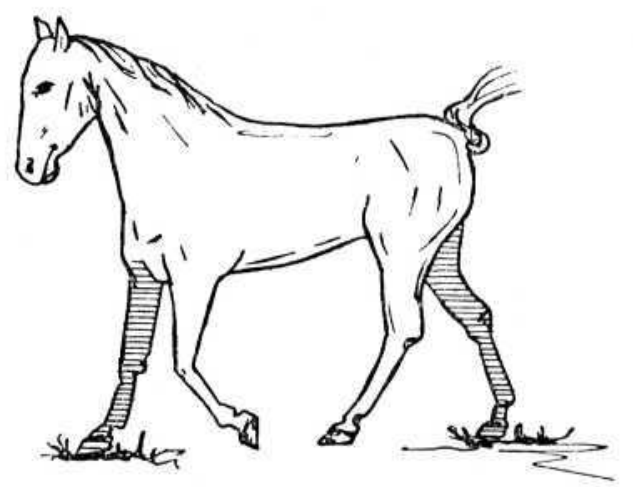

Fig. 10 
A disposição dos membros, em apôio lateral, na marcha, difere pouco da verificada no passo.

Na marcha, há tendência do bípede em sustentação divergir, desaparecendo a orientação vertical e paralela; enquanto que os membros em suspensão convergem, tal como no passo.

Das fases bipedais laterais, a única confusão possível de ser feita, pela disposição mais ou menos semelhante dos membros, quer em apôio, quer em suspensão, se refere à marcha e passo, pois que a orientação, na andadura é bem diversa.

Assim mesmo, já vimos a principal diferenciação entre as diversas modalidades parecidas.

$\left.2 .^{\circ}\right)$ - Diagonais

d) Apôio bipedal diagonal, no trote (fig. 11)

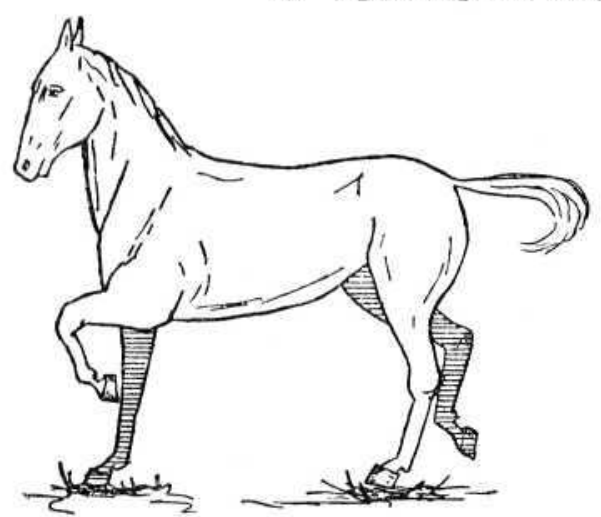

(a)

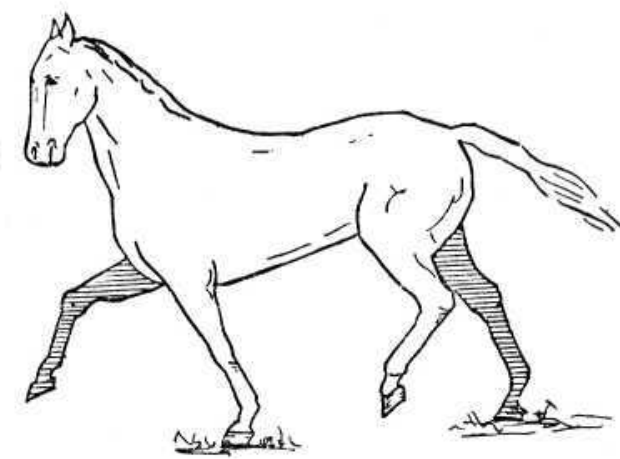

Fig. 11 (b)

O bípede diagonal, em apôio no trote normal, mantem-se paralelo, durante tôda a fase de oscilação, desde o início da sustentação, quando os membros são oblíquos de trás para frente (fig. 11a), até o final do período, em que os membros se tornam oblíquos de frente para trás (fig. 11b), passando pela fase intermediária, vertical.

Os membros em suspensão, o anterior localizado para frente de seu congênere em apôio, o posterior para trás, no início da fase bípedal diagonal (fig. 11a), e para frente no fim dessa fase (fig. 11b) têm flexão grande, como se pode perceber pelo fechamento dos ângulos do joelho e jarrete.

O deslocamento dos membros em suspensão para frente, abrindo os ângulos referidos, faz com que, no fim do período de apôio, como dissemos, ambos os membros em suspensão se localizem para frente do bipede em apôio (fig. 11-b). 


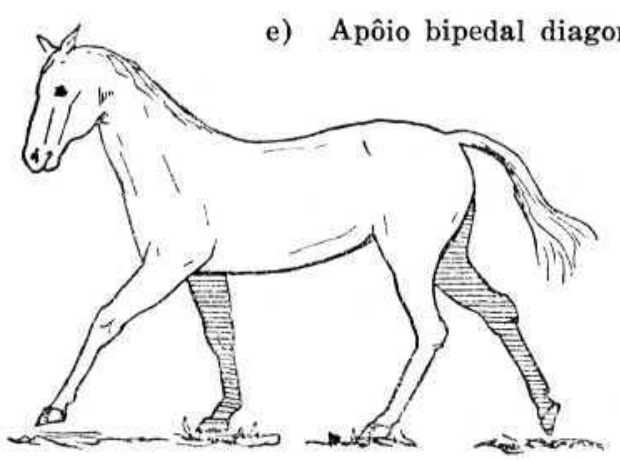

(a)

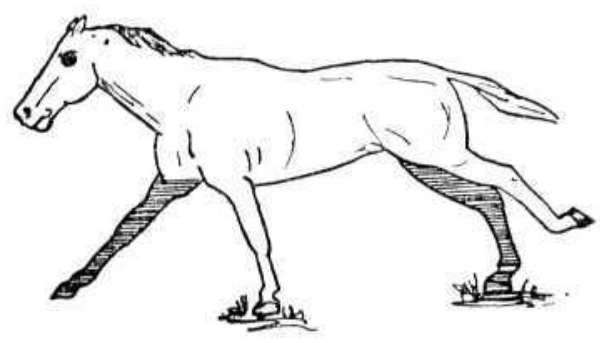

(b)

Fig. 12

A tendência dos membros diagonais em apôio, no galope normal, é convergir; e essa disposição tende a desaparecer, à medida que a velocidade do andamento aumenta, aumentando, assim, o terreno ganho.

Inverte-se, completamente, no galope de corrida, quando a orientação dos bípedes diagonais em apôio tende a divergir.

A parte livre dos membros em suspensão, o anterior para diante de seu congênere em apôio, o posterior para trás, tem ângulos abertos, o que determina membros distendidos.

f) Apôio bipedal diagonal, no passo (fig. 13)

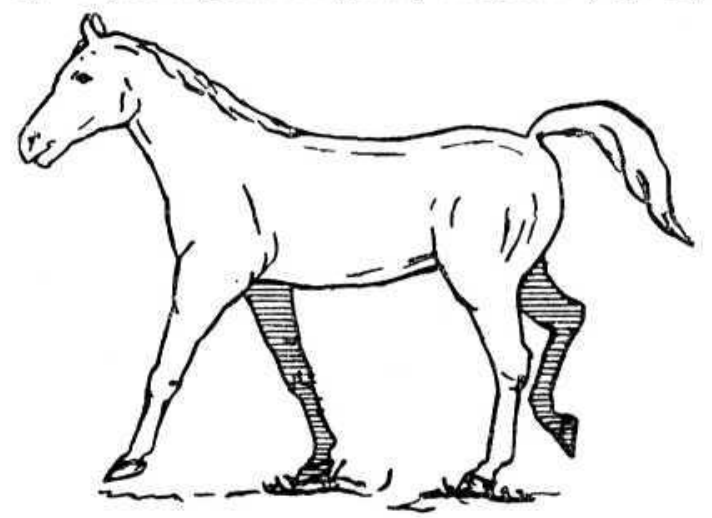

Fig. 13

No apôio bipedal diagonal do passo, os membros em apôio mantêm orientação convergente, o que se evidencia pela aproximação dos cascos que formam a base de sustentação, relativamente curta.

Em sua oscilação para frente chega um momento em que o bípede toma a posição da fig. 13, onde se verifica a convergência dos membros diagonais em sustentação, a extensão quasi máxima do mem- 
bro anterior em suspensão e a flexão bem acentuada do jarrete, no membro posterior, tambem em suspensão.

A simples observação das fases semelhantes nos demais andamentos, pelo exame dos esquemas, é suficiente para diferenciá-las. Com efeito, na fase de apôio bipedal diagonal do galope, única em que os bípedes tomam posição semelhante à agora descrita, o membro posterior em suspensão, no galope, se acha completamente distendido (fig. $12 \mathrm{a}$ e 12b).

g) Apôio bipedal diagonal, na marcha (fig. 14)

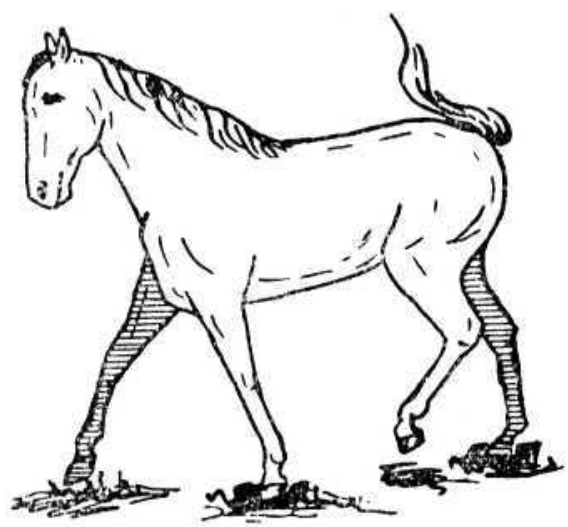

Fig. 14

A disposição que os membros tomam no período de sustentação diagonal, na marcha, é semelhante à verificada no trote normal, sendo impossível diferenciar os dois andamentos. Aliás, o animal filmado, do qual foi extraida a silhueta representada na fig. 14 possuia marcha trotada bem característica, com predominância dos apoios diagonais sôbre os demais, aproximando o andamento do trote.

$\left.3 .^{\circ}\right)$ - Posteriores

h) Apôio bipedal posterior, no galope de corrida (fig. 15)

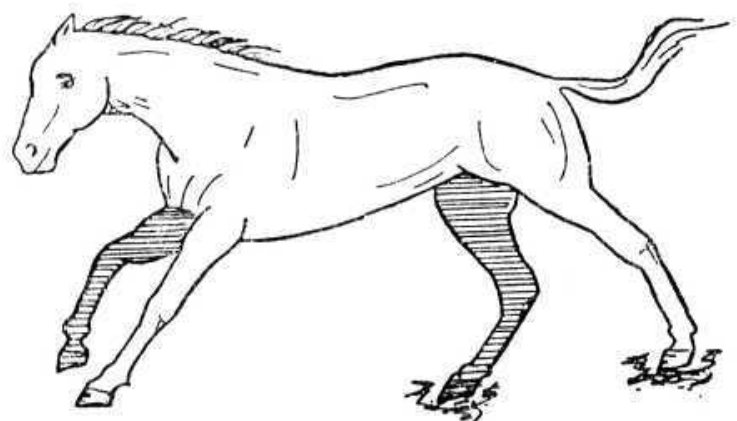

Fig. 15 
Só foi encontrado êsse apôio, no estudo dos andamentos, em uma modalidade do galope - o galope de corrida - sendo caracterizado pela sustentação dos membros pélvicos, um adiante do outro.

Os membros anteriores, em suspensão, não têm a mesma disposição; um se acha em máxima extensão e outro se apresenta flexionado no joelho.

Fase semelhante se nota, no período de preparação do salto e no empino, e nestes casos o trem anterior do animal se acha mais elevado.

$\left.4 .^{\circ}\right)$ - Anteriores

i) Apôio bipedal anterior, no galope de corrida (fig. 16)

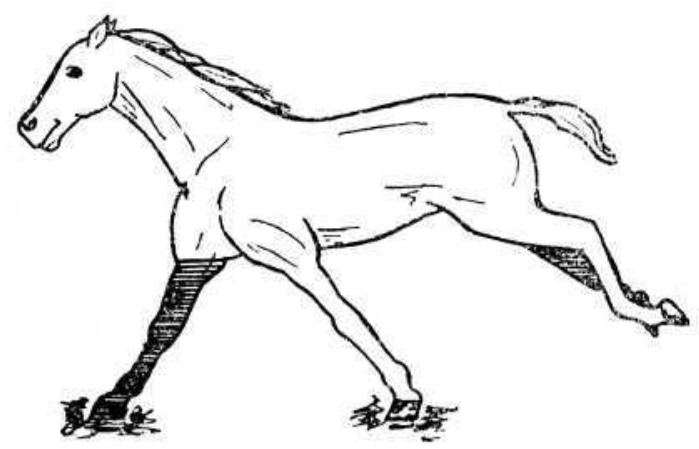

Fig. 16

Essa medalidade de apôio, tal como dissemos com referência à posterior que acabamos de descrever, sòmente aparece no galope de corrida.

Nela o bípede anterior se encontra em apôio, bem distendido, enquanto ambos os membros posteriores estão lançados para trás.

Na fase descendente do salto, após a passagem do obstáculo, há sustentação bipedal anterior e, neste caso, o bípede posterior, bem elevado, se acha mais ou menos flexionado e, às vezes, é lançado para um lado.

\section{$\left.1 .^{\circ}\right)$ - Anteriores}

\section{APOIOS TRIPEDAIS}

a) Apôio tripedal anterior, na andadura (fig. 17)

Pelo exame dessa figura, verificamos que o bípede lateral que forma, com o outro membro posterior, a base tripedal, tem orientação oblíqua para trás e se mantem paralelo, tal como na fase predominante do andar, referida quando analisamos a fig. 8. 
O único membro em suspensão, no caso anterior direito, se acha flexionado no joelho e não deixa de se colocar em orientação paralela, se considerarmos o raio ósseo do ante-braço, relativamente ao membro posterior do mesmo lado, embora êste se encontre em apôio.

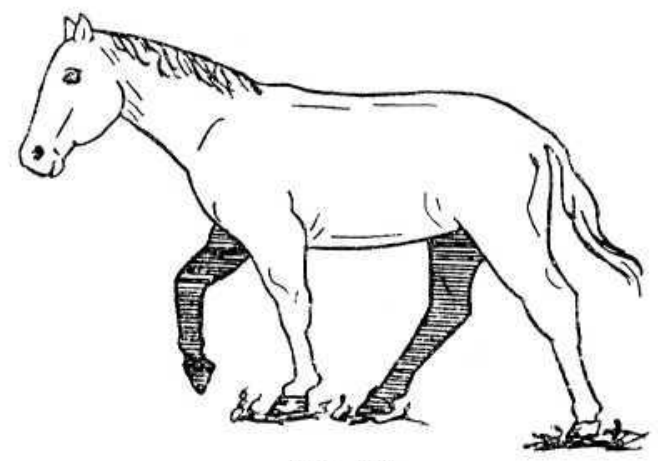

Fig. 17

b) Apôio tripedal anterior, no galope (fig. 18)

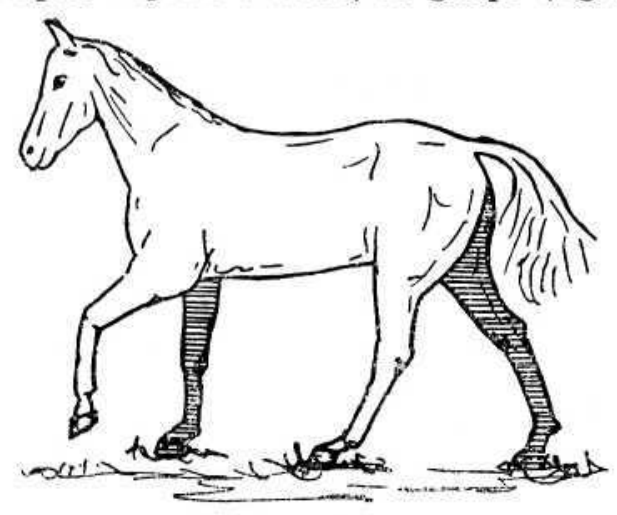

Fig. 18

Nesta fase do galope normal, o bípede lateral em apôio não mais acompanha a orientação paralela verificada e descrita na fig. 17. Ao contrário, enquanto o membro anterior toma direção mais ou menos vertical, o posterior é fortemente oblíquo para trás.

Quanto ao bípede lateral, do qual o anterior se acha em suspensão, a disposição é, poderiamos dizer, semelhante à verificada na fig. 17, seguindo orientação obliqua para frente, mais ou menos paralela.

A simples verificação do bípede lateral em apôio é, por conseguinte, suficiente para diferenciar as fases semelhantes do galope e andadura. 
c) Apôio tripedal anterior, no passo (fig. 19)

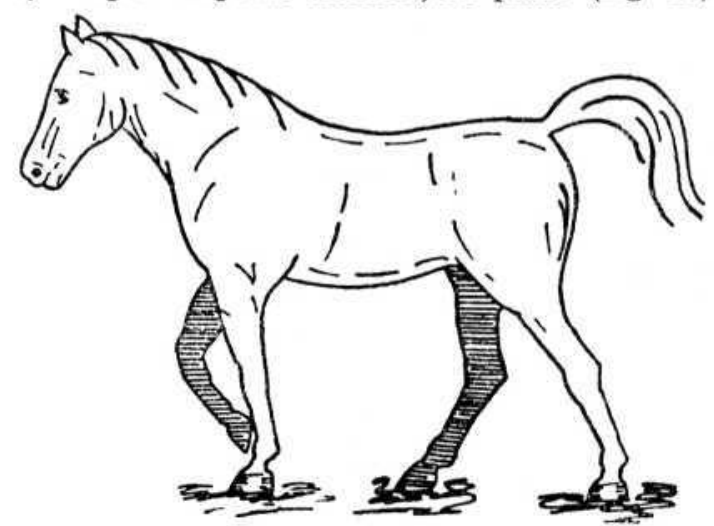

Fig. 19

Haveria certa dificuldade em diferenciar o andar, se passo ou galope, nessa base de sustentação, se não fosse o membro anterior em suspensão e, talvez, maior extensão do membro posterior que iniciou o passo, no galope.

Com efeito, a disposição dos membros em apôio é pràticamente semelhante em ambos os andamentos, bastando para nos convencermos, comparar as fig. 18 e 19.

No entanto, o membro anterior, no passo, (fig. 19) não está tão avançado como o mesmo membro no galope, (fig. 18) e essa disposição não chega a se modificar muito no decurso do passo, visto como essa base de apôio tripedal tem curta duração, desaparecendo pela elevação do membro posterior, no caso o esquerdo.

d) Apôio tripedal anterior, na marcha (fig. 20)

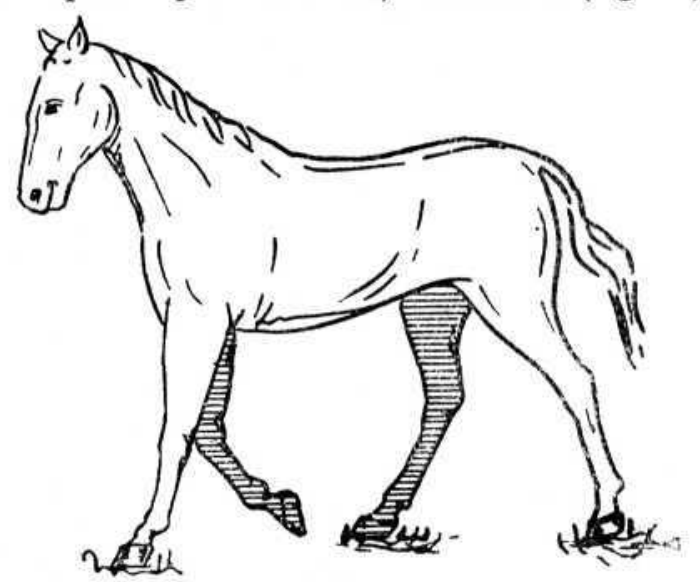

Fig. 20 
Em se tratando da marcha, a orientação dos membros é completamente diversa da que temos referido até agora, nessa fase de apôio.

$O$ bípede lateral que entra na constituição da base tripedal, diverge inferiormente, tal como vimos ao descrever a sutentação lateral da marcha (fig. 10).

O anterior em suspensão, se localiza para trás da linha de aprumo, enquanto que nos três casos já descritos, se localiza para frente dessa linha.

\section{$\left.2 .^{\circ}\right)$ - Posteriores}

e) Apôio tripedal posterior, na andadura (fig. 21)

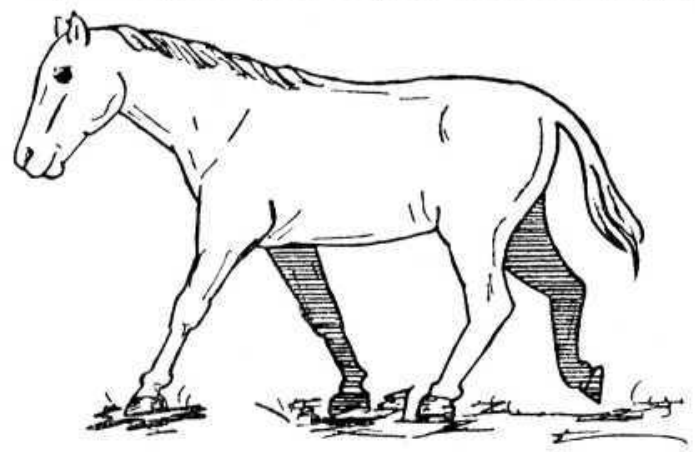

Fig. 21

A disposição dos membros em apôio, na fase tripedal posterior da modalidade de andadura ora estudada, é idêntica à descrita na fig. 17 apenas se diferenciando pelo membro em suspensão, que no caso da fig. 17 é anterior e se acha deslocado para frente da linha de aprumo, enquanto que na fig. 21, o membro em suspensão é um posterior e o deslocamento se verifica para trás da linha de aprumo, apenas flexionado na jarrete.

f) Apôio tripedal posterior, no galope (fig. 22)

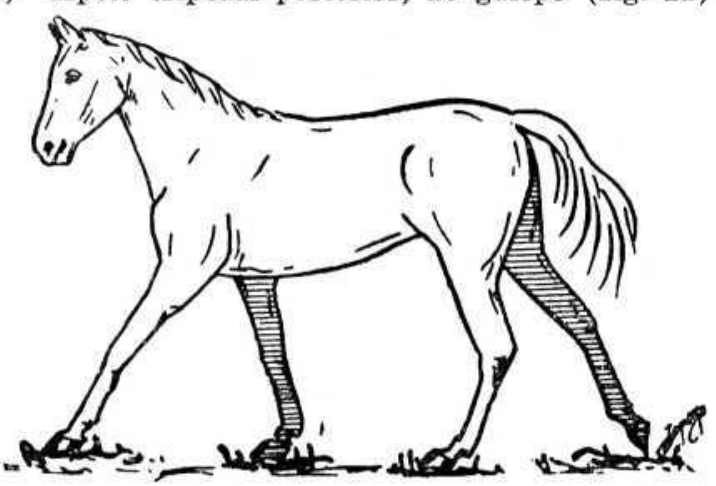

Fig. 22 
O bípede diagonal que, conjuntamente com o outro membro anterior forma a fase tripedal posterior do galope normal, converge inferiormente, e o outro bípede diverge, tal como verificamos na fig. 21.

O posterior em suspensão se acha francamente estendido, diferenciando essa fase da base de apôio semelhante, na andadura, onde êsse mesmo membro se acha flexionado no jorrete, com tendência a um maior fechamento.

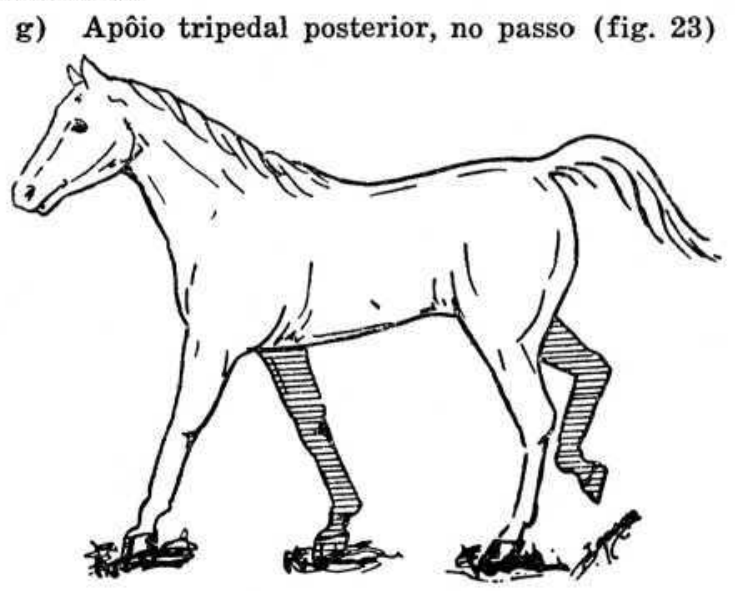

Fig. 23

A disposição dos membros em apôio se assemelha à verificada nas figuras 21 e 22 .

A diferenciação evidente se nota no membro posterior em suspensão, que, no passo, apresenta ângulo do jarrete bem fechado, mais do que na andadura.

APÔIO QUADRUPEDAL

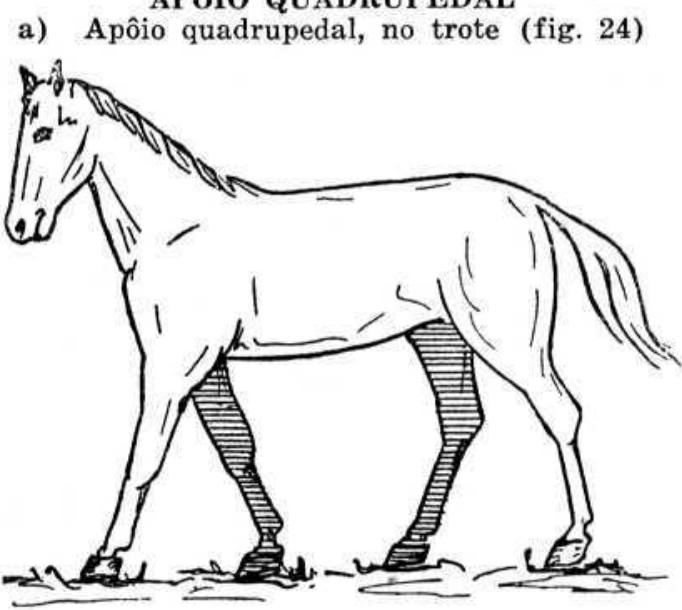

Fig. 24 
A orientação dos bípedes laterais, no apôio quadrupedal do trote marchado é inversa, de modo que, enquanto um converge inferiormente, (no caso, o bípede lateral direito) o outro diverge, e a disposição que encontramos é a verificada na fig. 24 que lembra o período de suspensão do trote, com exceção, lògicamente da orientação da parte terminal dos membros.

PERÍODO DE SUSPENSAO

a) Período de suspensão, no trote (fig. 25)

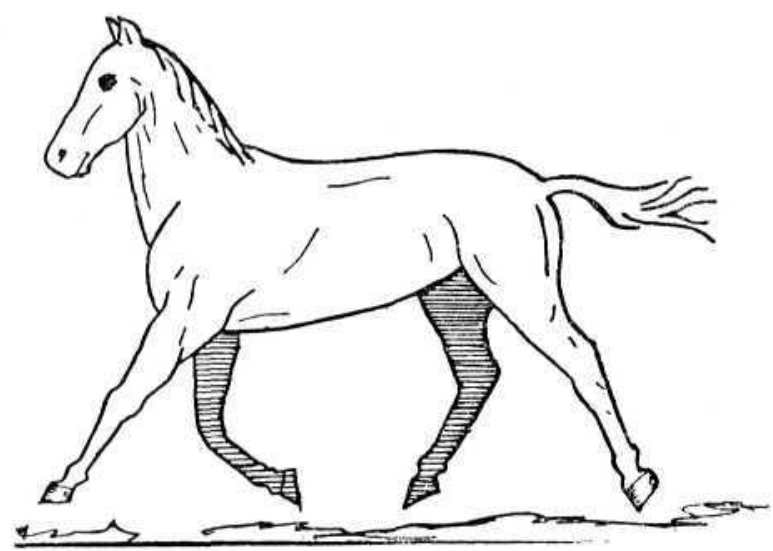

Fig. 25

Em virtude dos bípedes diagonais se associarem, na queda e suspensão do trote, a fase de suspensão dêsse andamento se caracteriza pela permanência de um certo paralelismo dos raios ósseos dos bípedes diagonais. Verificamos, então, que, enquanto um bípede lateral converge inferiormente, o outro diverge, e, lògicamente, êste apresenta ângulos do joelho e jarrete flexionados, o oposto se verificando naquêle.

b) Período de suspensão, no galope (fig. 26)

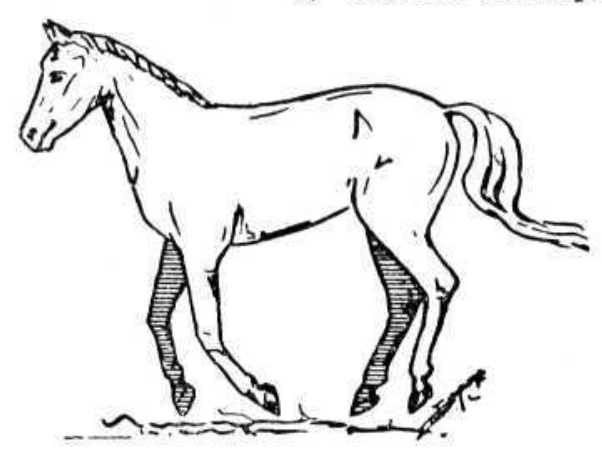

(a)

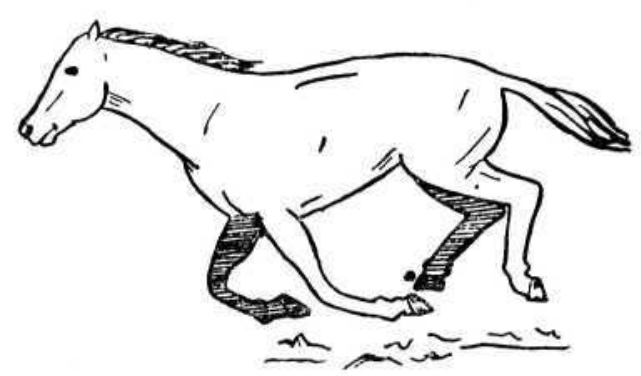

(b)

Fig. 26 
No galope, contràriamente ao que verificamos no trote, os quatro membros se encontram sempre flexionados sob o corpo, notandose um bípede lateral (o do posterior que iniciará o passo) ligeiramente adeante do outro.

A flexão dos ângulos e o agrupamento dos membros se acentua, cada vez mais, a medida que a velocidade aumenta e chega ao seu máximo no galope de corrida (fig. 26-b).

c) Período de suspensão, na andadura de corrida (fig. 27))

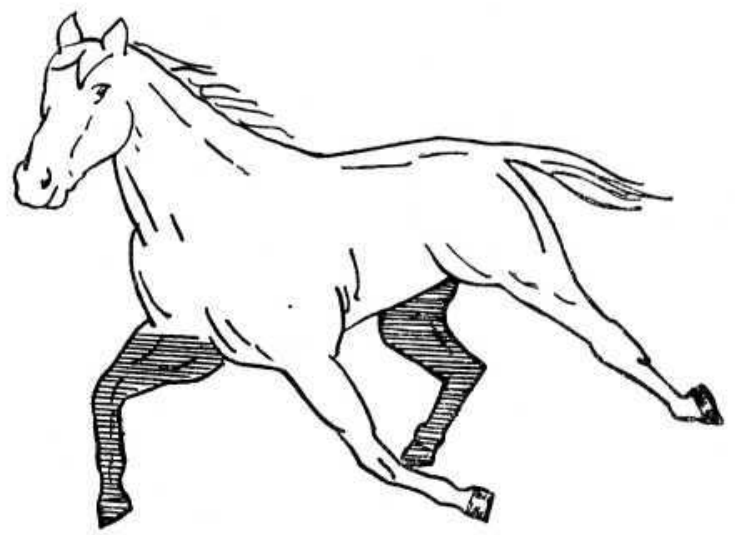

Fig. 27

Tal como verificamos nas outras fases de apôio já descritas da andadura, os bípedes laterais, mesmo na variedade de andadura de corrida - "pacing", - conservam a orientação mais ou menos paralela e inclinada.

A disposição dos membros, nos três tipos de suspensão referidos, serve para caracterizar perfeitamente os andamentos, não havendo possibilidade de confusão por não existir semelhança alguma.

\section{RESUMO}

O Autor, reportando-se ao estudo das bases de apôio e suspensão, nos diversos andamentos do cavalo, feito em trabalho já publicado, declara ter tido sua atenção voltada para a existência de bases de sustentação e de períodos de suspensão semelhantes, nos diversos tipos de locomoção.

A simples notação, que representa gràficamente as fases de apôio e de suspensão dos membros nos andamentos, não será capaz de diferenciar as modalidades. 
O autor propôs-se, então, interpretar as películas do Departamento de Zootecnia Especial da Faculdade de Medicina Veterinária da Universidade de São Paulo, que focalizam animais em câmara lenta, obtendo, por decalque dos filmes, as silhuetas que ilustram o trabalho.

As figuras foram catalogadas de acôrdo com o número de membros em apôio seguindo, assim, a ordem de apoios monopedais (posterior e anterior) ; apoios bipedais (laterais e diagonais), apoios tripedais (anterior e posterior); apôio quadrupedal e período de suspensão.

Após a discussão da matéria, explicando o mecanismo de aparecimento das fases de apôio e suspensão semelhantes nos diversos andamentos, o Autor faz um estudo comparativo dessas fases, baseando-se na disposição que tomam os membros, procurando diferenciar, pela orientação dos raios ósseos, os tipos de locomoção.

Esse trabalho, além de servir como contribuição ao estudo, sempre interessante, da locomoção animal, poderá orientar a representação artística de um cavalo em andamento, pois o Autor se refere às interpretações falhas e inexistentes que muitas vezes se encontram em pinturas e esculturas.

O Autor não trata da angulação máxima e mínima das articulações da parte livre dos membros, adeantando que êsse assunto faz parte de outro trabalho de sua autoria ora em preparo, que conta com a colaboração do Drs. Orlando Marques de Paiva e Plinio Pinto e Silva.

\section{SUMMARY}

The Author, after referring to an already published study of the periods of support and suspension in the various gaits of the horse, states that his attention was drawn to the existence of similarities between the preiods of suport and suspension in the various types of locomotion.

The notation alone, though it represents graphically the phases of support and suspension of the limbs, is inadequate to distinguish the various types of locomotion.

The author, therefore, undertook to interpret the films taken by Special Zootechnics Department of the Faculty of Veterinary Medicine showing animals in slow motion (at the rate of 64 exposures a second), and made the tracings that illustrate this paper.

The tracing were grouped accoding to the number of limbs in contact with the ground, as follows: monopedal support (posterior or anterior); bipedal support (lateral or diagonal); tripedal support (anterior or posterior); quadrupedal support and period of suspension. 
After discussing the mechanics of the appearence of similar phases of support and suspension in the gaits, the author makes a comparative study of these phases, based on the disposition of the limbs, the direction of which he takes as a criterion for the classification of the various gaits.

This paper, in addition to being a contribution to the everinteresting study of animal locomotion, may serve as a guide in the artistic representation of horse in motion, the author mentioning the many mistakes and omissions that we often see in pictures and sculptures.

The author does not deal with the maximum and minimum angles of the articulations of the free part of the limbs, as this subject is incorporated in another paper, now in preparation, written in collaboration with Drs. Orlando Marques de Paiva, and Plinio Pinto e Silva. 